\title{
Biological, Serological, and Molecular Differences Among Isolates of Potato A Potyvirus
}

\author{
M. Rajamäki, A. Merits, F. Rabenstein, J. Andrejeva, L. Paulin, \\ T. Kekarainen, J. F. Kreuze, R. L. S. Forster, and J. P. T. Valkonen
}

First, second, fifth, sixth, seventh, and ninth authors: Institute of Biotechnology, Viikki Biocenter 1, P.O. Box 56, FIN-00014 University of Helsinki, Finland; third author: Bundesanstalt für Züchtungsforschung an Kulturpflanzen, Institut für Resistenzforschung und Pathogendiagnostik, Postfach 1505, D-06435 Aschersleben, Germany; fourth author: Institute of Biotechnology, Viikki Biocenter 1, P.O. Box 56, FIN-00014 University of Helsinki, Finland, and Institute of Chemical Physics and Biophysics, Akadeemia tee 23, EE0026, Tallinn, Estonia; and eighth author: The Horticultural and Food Research Institute of New Zealand Ltd., Mt. Albert Research Centre, 120 Mt. Albert Road, Private Bag 92 169, Auckland, New Zealand.

Accepted for publication 8 December 1997.

\begin{abstract}
Rajamäki, M., Merits, A., Rabenstein, F., Andrejeva, J., Paulin, L., Kekarainen, T., Kreuze, J. F., Forster, R. L. S., and Valkonen, J. P. T. 1998. Biological, serological, and molecular differences among isolates of potato A potyvirus. Phytopathology 88:311-321.

Sequences of the coat protein $(\mathrm{CP})$ and $3^{\prime}$-end nontranslated region ( $\left.3^{\prime} \mathrm{NTR}\right)$ of 13 isolates and the helper component proteinase (HC) of nine isolates of potato A potyvirus (PVA) were determined and compared with the eight previously determined PVA CP and 3'NTR sequences and one HC sequence. CP amino acid (aa), 3’NTR nucleotide, and $\mathrm{HC}$ aa sequence identities were $92.9,93.4$, and $94.8 \%$, respectively. Sequence data, serological tests, and the necrotic local lesions induced in the leaves

of the potato hybrid 'A6' confirmed that tamarillo mosaic virus is a strain of PVA. The aa substitutions A6T and G7S in the CP N-terminus were correlated with loss of aphid transmissibility. Development of necrotic lesions or nonnecrotic symptoms in the systemically infected leaves or lack of systemic spread in potato cv. King Edward were used to place the PVA isolates into four strain groups, but this grouping was not correlated with any differences in CP, HC, or 3'NTR. Recognition of CP by three monoclonal antibodies was used to place the PVA isolates into three groups different from the four groups above. The epitopes of two monoclonal antibodies were mapped by site-directed mutagenesis to the same lysine residue at the $\mathrm{CP}$ aa 34 .
\end{abstract}

Potato A potyvirus (PVA) is widely distributed in the potatogrowing areas of Europe and North America (26). Its natural occurrence and economic importance are mostly restricted to the cultivated potato (Solanum tuberosum L.; family Solanaceae) $(7,31)$. Yield losses caused by PVA in potato can reach up to $40 \%$ (26). However, yield losses can be greater when PVA is in mixed infections with potato $\mathrm{X}$ potexvirus (PVX), which causes a crinkle disease in potato $(26,31)$. Recently, PVA has become more prevalent in some potato-production areas $(9,46)$, possibly because virus indexing is no longer carried out using sensitive indicator hosts such as 'A6' ( $S$. demissum Lindl. $\times S$. tuberosum cv. Aquila) (15, $26,47)$ but is entirely based on serological tests that can be insensitive $(9,22)$.

PVA shares the common properties of the genus Potyvirus (family Potyviridae), which contains approximately 180 definite and possible members and is the largest and economically the most important group of plant viruses (41). The complete nucleotide sequence of the PVA isolate B11 has been determined (35). The filamentous virions of PVA consist of a monopartite genome of single-stranded, positive-sense RNA (9,565 nucleotides [nt]) that is encapsidated by the virus-encoded coat protein (CP). The RNA genome is translated into a polyprotein (3,059 amino acids [aa]) that is subsequently processed into up to 10 functional proteins. PVA CP (269 aa) is produced from the C-terminal part of the polyprotein (34). The N-terminal part of the PVA CP (2) and other potyviruses (40) is exposed on the virion surface and is the im-

Corresponding author: J. P. T. Valkonen; E-mail address: jari.valkonen@vbiol.slu.se

Publication no. P-1998-0127-01R

(C) 1998 The American Phytopathological Society munodominant region responsible for serological variability. In sugarcane mosaic potyvirus, sequence diversity in the CP N-terminus is correlated with host range and other biological properties (50). PVA CP contains an aspartic acid-alanine-glycine (DAG) sequence (3), which, in other potyviruses, has been shown to be required for aphid transmissibility $(6,23,25)$. However, the helper component proteinase (HC) is also required for aphid transmissibility of potyviruses $(27,43)$. The potyvirus $\mathrm{CP}$ is required for viral cell-to-cell and long-distance movement (17), whereas HC is involved in long-distance movement, virus replication, and symptom expression $(4,5,30,32)$. Like other potyviruses, the $3^{\prime}$ end of the PVA genome contains a nontranslated region ( $\left.3^{\prime} \mathrm{NTR}\right)$ that ends with a poly(A) tail (35). Length of the PVA $3^{\prime}$ NTR varies among PVA isolates (227 or $229 \mathrm{nt}$ ) (3). Previous studies have indicated that potyvirus $3^{\prime}$ NTR is involved in the initiation of minus-strand RNA synthesis (10) and can affect the severity of virus-induced symptoms (38).

Biological and molecular variability in PVA is not well documented, because most of the previous studies have not examined both biological and molecular properties of the same isolates (11, 13,31,34,35). However, one study (47) has compared the CP sequences of the PVA isolates $\mathrm{U}, \mathrm{M}$, and B11 and their phenotypic responses in potato cvs. King Edward, Maris Piper, and Pentland Dell. These cultivars are known to react with a hypersensitive resistance response (HR) (24) to infection with PVA based on the development of necrotic lesions in the upper leaves following graft inoculation $(29,45)$. The gene $N a(+1 /-2)$ (previous name $N a_{K E}$ ) $(45,47)$ in 'King Edward' is induced by the PVA isolate $U$ but not $\mathrm{M}$, whereas the gene $\mathrm{Na}(+1,2)$ (previous name $N a)(45,47)$ in 'Maris Piper' and 'Pentland Dell' is induced by both PVA isolates; isolates $\mathrm{U}$ and $\mathrm{M}$ were proposed to be type strains of the PVA 
strain groups 1 and 2, respectively, based on the above-mentioned difference in the reaction of 'King Edward' (47). Potato cv. Pentland Ivory did not react with HR to infection with PVA isolates $\mathrm{U}$ and $\mathrm{M}$, but a systemic symptomless infection developed. The PVA isolate B11 neither induced any symptoms nor infected systemically any of the above-mentioned potato cultivars and was proposed to represent PVA strain group 3 (47). Whether these differential reactions in potato plants were attributable to the differences detected in the CP gene sequences (47) is not reported. Another study on the N-terminal CP sequences of 11 PVA isolates has shown that, as with other potyviruses, the DAG motif in the $\mathrm{N}$-terminus of PVA CP correlates with aphid transmissibility of PVA $(2,3)$, but other biological properties of these PVA strains (except isolate B11) have not been studied.

In this work, PVA isolates maintained in different host species and originating from different geographic areas were studied to (i) determine host plant responses, aphid transmissibility, and serological properties; (ii) determine intraspecies variability by comparison of the CP- and HC-encoding and 3'NTR sequences; and (iii) examine how any differences in the biological and serological properties correlated with differences in the viral sequences analyzed.

\section{MATERIALS AND METHODS}

PVA isolates. The isolates of PVA used in this study are listed in Table 1. The isolates 716/12 (ATCC PV-266; type strain of PVA), Adv, Ali, and Dat were isolated at the BBA Braunschweig, Braunschweig, Germany, and maintained in tobacco plants (Nicotiana tabacum) by mechanical inoculation. Adv and Ali were isolated in 1978, and 716/12 and Dat were isolated earlier (year unknown). Isolate 716/12 was deposited at the American Type Culture Collection (ATCC), Rockville, MD, in 1978, where it has been propagated twice by mechanical inoculation in tobacco, and from where it was obtained for this study in infected, freeze-dried tobacco leaves. Isolates Adv, Ali, and Dat were obtained from the Institute of Plant Breeding Research and Pathogen Diagnostics, Aschersleben, Germany, which had received these isolates from BBA Braunschweig in 1984. In Aschersleben, the PVA isolates have been maintained in different Nicotiana spp. through approximately 30 passages (four passages per year) by mechanical inoculation. The iso- late B11 was sent to Aschersleben from Hungary in 1983 (precise origin unknown) and was maintained in a similar manner as the isolates Adv, Ali, and Dat. For this study, virions of isolate B11 were produced in tobacco plants using transcripts of the full-length infectious cDNA clone of the PVA isolate B11 (B11-icDNA) (36). Isolate TamMV was originally isolated from tamarillo (Cyphomandra betacea (Cav.) Sendtn.; recently renamed Solanum betaceum Cav.) (8), maintained in Nicotiana spp. (18), and propagated in $N$. tabacum cv. Samsun by mechanical inoculation. Mechanical inoculations with PVA were carried out as previously described (47).

Isolate Can (13) was provided in infected potato leaves by R. P. Singh, Agriculture Canada, Fredericton. Isolate Pen was provided in infected leaves of potato cv. Penta and isolate Pon was provided in infected tobacco leaves by I. A. Browning, Scottish Agricultural Science Agency (SASA), Edinburgh, United Kingdom. Isolates Afg, Alc, Jul, Lin, and Sro were provided in infected potato tubers by J. F. J. M. van den Heuvel, Research Institute for Plant Protection (IPO-DLO), Wageningen, the Netherlands. Isolates Her, Pit, Sab, and Tan were provided in infected potato tubers by J. P. Palohuhta, Seed Potato Center, Tyrnävä, Finland. Isolate A20 was isolated from a potato tuber received from the Scottish Crop Research Institute, Invergowrie, United Kingdom. Tubers were planted in soil in the greenhouse. All of the above-mentioned PVA isolates were mechanically inoculated to tobacco plants. Fourteen days later, one symptomless, noninoculated top leaf was sampled, and half was tested with double-antibody sandwich-enzyme-linked immunosorbent assay (DAS-ELISA) (12) for PVA, potato Y potyvirus (PVY), PVX, and potato $\mathrm{S}$ and $\mathrm{M}$ carlaviruses using virusspecific polyclonal antibodies (PAb) and alkaline phosphatase (AP)conjugated $\mathrm{PAb}$ purchased from Boehringer $\mathrm{GmbH}$, Mannheim, Germany. Additionally, the samples were tested for potato $\mathrm{V}$ potyvirus (PVV) by DAS-ELISA using the monoclonal antibody (MAb) 53/8 and AP-conjugated MAb to PVV obtained from I. A. Browning, SASA, Edinburgh, United Kingdom. If only infected with PVA, the other half of the tested tobacco leaf was used for inoculation of potato $\mathrm{cv}$. Pito, in which the isolates were maintained (Table 1). Isolates $U$ and $M(47)$ were originally provided by S. A. Slack, Cornell University, Ithaca, NY, and F. Mehdizadegan, Maine Department of Agriculture, respectively, and have since been maintained in our collection in potato cv. Pito.

TABLE 1. Potato A potyvirus isolates included in this study

\begin{tabular}{|c|c|c|c|c|c|c|c|}
\hline Isolate & $\begin{array}{l}\text { Original source } \\
\text { (potato cultivar) }\end{array}$ & Country of origin & $\begin{array}{l}\text { Donor; } \\
\text { literature citation (lit. cit.) }\end{array}$ & $\begin{array}{l}\text { Propagation host } \\
\text { in this study }\end{array}$ & $\begin{array}{c}\mathrm{CP} \\
\text { (lit. cit.) }\end{array}$ & $\begin{array}{l}3^{\prime} \mathrm{NTR}^{\mathrm{b}} \\
\text { (lit. cit.) }\end{array}$ & $\begin{array}{c}\text { EMBL } \\
\text { accession no. }\end{array}$ \\
\hline B11 & Not reported & Hungary & 34 & Samsun & 34 & 34 & $\mathrm{Z} 21670$ \\
\hline $716 / 12$ & Endgold & Germany & $\mathrm{ATCC}^{\mathrm{c}}$ & Samsun & This study & This study & Y11427 \\
\hline Adv & Advira & Germany & 3 & Samsun & $3^{d}$ & This study & Y10250 \\
\hline Ali & Ali & Germany & 3 & Samsun & 3 & 3 & X91966 \\
\hline Dat & Datura & Germany & 3 & Pito & $3^{d}$ & This study & Y11426 \\
\hline Can & Not reported & Canada & R. Singh; 13 & Pito & 13 & 13 & S51667 \\
\hline Her & Hertha & Finland & 46 & Pito & This study & This study & Y11421 \\
\hline Pit & Pito & Finland & J. P. Palohuhta & Pito & This study & This study & Y11420 \\
\hline $\mathrm{Sab}$ & Sabina & Finland & J. P. Palohuhta & Pito & This study & This study & Y10126 \\
\hline Tan & Hankkijan Tanu & Finland & J. P. Palohuhta & Pito & This study & This study & Y11425 \\
\hline Afg & Allerfrüheste Gelbe & The Netherlands & J. F. J. M. van den Heuvel & Pito & This study & This study & Y10125 \\
\hline Alc & Alpha & The Netherlands & J. F. J. M. van den Heuvel & Pito & This study & This study & Y11422 \\
\hline Jul & Juliniere & The Netherlands & J. F. J. M. van den Heuvel & Pito & 3 & 3 & X91968 \\
\hline Lin & Lichte Industrie & The Netherlands & J. F. J. M. van den Heuvel & Pito & $3^{\mathrm{d}}$ & This study & Y11423 \\
\hline Sro & Saucisse Rouge & The Netherlands & J. F. J. M. van den Heuvel & Pito & 3 & 3 & X91967 \\
\hline A20 & Not reported & United Kingdom, Scotland & This study & Pito & This study & This study & Y10079 \\
\hline Pen & Penta & United Kingdom, Scotland & I. Browning & Pito & This study & This study & Y11424 \\
\hline Pon & Red Pontiac & United Kingdom, Scotland & I. Browning & Pito & This study & This study & Y11428 \\
\hline M & BelRus & United States & 47 & Pito & 47 & 47 & Z49088 \\
\hline $\mathrm{U}$ & Line M700-14 & United States & 47 & Pito & 47 & 47 & Z49087 \\
\hline TamMV & Tamarillo (C. betacea) & New Zealand & 18 & Samsun & 18 & 18 & X54804 \\
\hline
\end{tabular}

a Nicotiana tabacum cv. Samsun; Solanum tuberosum cv. Pito.

b $3^{\prime}$ NTR = 3'-end nontranslated region.

c Type strain 716/12 ( ATCC PV-266) obtained from the American Type Culture Collection, Rockville, MD.

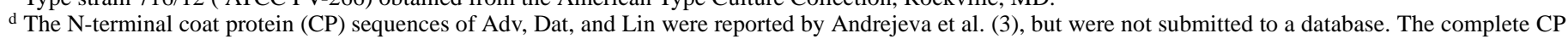
sequence was determined in this study. 
Virus purification. The PVA isolate B11 was purified from infected leaves of tobacco, and the PVA isolates U and Sab were purified from infected leaves of potato cv. Pito essentially as described by Fribourg and Nakashima (21) and modified by Browning et al. (9). Virus (or CP) concentrations in the purified preparations were determined spectrophotometrically and by sodium dodecyl sulfate-polyacrylamide gel electrophoresis (SDS-PAGE) (39).

Virus inoculation. The resistance genes and expected reactions to potyvirus infections in the potato genotypes used in this study as differentials have been reported previously (45-47). These

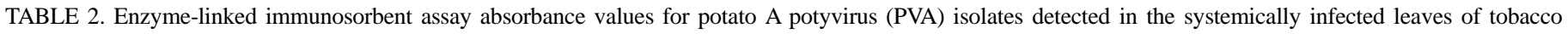
(Nicotiana tabacum cv. Samsun) using polyclonal antibodies (PAb) and the monoclonal antibodies (MAb) 58/0, 58/6, and 58/7 17 days after mechanical inoculation

\begin{tabular}{|c|c|c|c|c|c|c|c|c|c|}
\hline \multirow[b]{2}{*}{ PVA isolate } & \multicolumn{2}{|c|}{ Experiment $1^{\mathrm{a}}$} & \multicolumn{2}{|c|}{ Experiment $2^{\mathrm{b}}$} & \multicolumn{2}{|c|}{ Experiment $3^{\mathrm{c}}$} & \multicolumn{3}{|c|}{ Experiment $4^{\mathrm{d}}$} \\
\hline & $\mathrm{PAb}$ & MAb 58/0 & $\mathrm{PAb}$ & MAb 58/0 & MAb 58/0 & MAb 58/6 & MAb 58/0 & MAb 58/6 & MAb 58/7 \\
\hline B11 & $>2$ & $>2$ & 1.27 & 1.42 & 3.31 & 0.00 & 2.32 & 0.01 & 3.03 \\
\hline $716 / 12$ & $\mathrm{nt}^{\mathrm{g}}$ & 1.57 & 0.93 & $>2$ & 3.35 & 0.01 & 1.92 & 0.00 & 2.80 \\
\hline Dat & $\mathrm{nt}$ & 1.53 & 1.05 & 1.63 & 3.27 & 0.01 & 2.21 & 0.01 & 3.34 \\
\hline Adv & 1.04 & nt & nt & $>2$ & $\mathrm{nt}$ & nt & 0.28 & 0.01 & 0.20 \\
\hline Ali & 0.60 & $\mathrm{nt}$ & 1.16 & 0.79 & nt & $\mathrm{nt}$ & 2.18 & 0.02 & 3.10 \\
\hline $\mathrm{U}$ & 0.44 & 1.53 & 0.33 & 0.63 & 2.78 & 0.76 & 1.54 & 0.63 & 1.11 \\
\hline M & 0.71 & 1.88 & $\mathrm{nt}$ & 0.53 & nt & nt & nt & nt & nt \\
\hline Can & 0.28 & 0.37 & 0.29 & 0.31 & 1.31 & 0.34 & 0.56 & 0.20 & 0.34 \\
\hline $\mathrm{Sab}$ & 0.36 & 0.01 & 0.10 & 0.02 & 0.03 & 2.03 & 0.01 & 2.31 & 0.00 \\
\hline Pit & 0.57 & 0.00 & 0.10 & 0.01 & $\mathrm{nt}$ & nt & 0.00 & 0.28 & 0.01 \\
\hline Her & 0.55 & 0.01 & 0.50 & 0.00 & $\mathrm{nt}$ & nt & 0.01 & 0.46 & 0.00 \\
\hline Alc & 0.40 & 0.80 & nt & $\mathrm{nt}$ & $\mathrm{nt}$ & $\mathrm{nt}$ & nt & nt & nt \\
\hline Lin & 0.69 & 0.58 & 0.51 & $\mathrm{nt}$ & $\mathrm{nt}$ & $\mathrm{nt}$ & 0.37 & 0.10 & 0.13 \\
\hline Pen & 0.31 & 0.58 & 0.64 & 1.94 & $\mathrm{nt}$ & $\mathrm{nt}$ & 1.90 & 0.37 & 2.29 \\
\hline Tan & 0.53 & 1.21 & nt & 0.59 & nt & nt & 0.24 & 0.01 & 0.17 \\
\hline Afg & 0.53 & 0.85 & nt & nt & nt & nt & nt & $\mathrm{nt}$ & $\mathrm{nt}$ \\
\hline Jul & 0.35 & 0.64 & 0.11 & 0.13 & 1.14 & 0.15 & 0.69 & 0.16 & 0.31 \\
\hline A20 & $\mathrm{nt}$ & nt & 0.44 & 0.53 & $\mathrm{nt}$ & nt & 0.29 & 0.01 & 0.12 \\
\hline Pon & 0.54 & 0.76 & 0.19 & 0.60 & 1.07 & 0.19 & 0.84 & 0.26 & 0.51 \\
\hline Sro & 0.57 & 0.45 & 0.54 & 0.16 & 0.39 & 0.09 & 0.58 & 0.07 & 0.50 \\
\hline TamMV & 0.26 & 1.50 & nt & nt & 3.25 & 0.01 & 0.78 & 0.00 & 0.46 \\
\hline Noninfected leaves & 0.03 & 0.00 & 0.04 & 0.01 & 0.02 & 0.02 & 0.01 & 0.00 & 0.00 \\
\hline $\mathrm{LSD}_{0.05^{\mathrm{h}}}$ & 0.17 & 0.34 & 0.19 & 0.21 & 0.23 & 0.30 & 0.14 & 0.16 & 0.27 \\
\hline
\end{tabular}

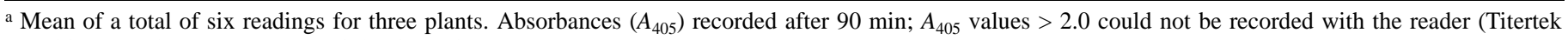
Multiscan; Labsystems, Espoo, Finland) used.

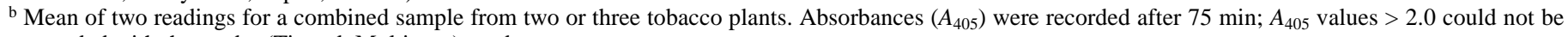
recorded with the reader (Titertek Multiscan) used.

${ }^{c}$ Mean of a total of six readings for three plants. Absorbances $\left(A_{405}\right)$ recorded after 75 min.

${ }^{\mathrm{d}}$ Mean of two readings for a combined sample from two or three tobacco plants.

e Absorbances $\left(A_{405}\right)$ recorded after $40 \mathrm{~min}$.

f Absorbances $\left(A_{405}\right)$ recorded after $4 \mathrm{~h}$.

${ }^{\mathrm{g}} \mathrm{nt}=$ not tested.

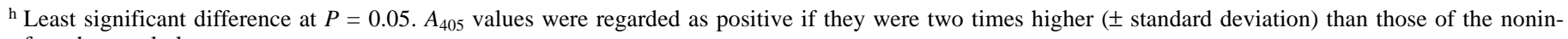
fected control plants.

TABLE 3. Symptoms in tobacco and potato plants inoculated with the potato A potyvirus (PVA) isolates ${ }^{\mathrm{a}}$

\begin{tabular}{|c|c|c|c|c|c|c|c|}
\hline \multirow[b]{2}{*}{ PVA isolate } & \multicolumn{2}{|c|}{ Mechanically inoculated } & \multicolumn{4}{|c|}{ Side-graft-inoculated potato cultivars } & \multirow[b]{2}{*}{ PVA strain group } \\
\hline & Tobacco cv. Samsun & Potato hybrid 'A6' & King Edward & Maris Piper & Pentland Dell & Pentland Ivory & \\
\hline B11 & SSI & NLL & ni & ni & ni & ni & 3 \\
\hline $716 / 12$ & SSI & NLL & NLcm & NL & NL & ni & 1 \\
\hline Dat & SSI & NLL & NLcm & $\mathrm{NL}$ & $\mathrm{NL}$ & SSI & 1 \\
\hline Adv & SSI & NLL & ni & ni & ni & SSI & 3 \\
\hline Ali & SSI & NLL & Mo & NL & NL & ni & 2 \\
\hline $\mathrm{U}$ & SSI & NLL & $\mathrm{NLcm}$ & NL & NL & SSI & 1 \\
\hline M & SSI & NLL & Mo & ni & NL & SSI & 2 \\
\hline Can & SSI & NLL & CSnc, Y, Stu & NL & NL & SSI & 4 \\
\hline $\mathrm{Sab}$ & SSI & NLL & $\mathrm{NL}$ & NL & NL & SSI & 1 \\
\hline Pit & SSI & NLL & NL & NL & NL & SSI & 1 \\
\hline Her & SSI & NLL & $\mathrm{NL}$ & NL & NL & SSI & 1 \\
\hline Alc & SSI & NLL & NLcm & NL & NL & SSI & 1 \\
\hline Lin & SSI & NLL & NLcm & NL & NL & SSI & 1 \\
\hline Pen & SSI & NLL & CSnc, Y, Stu, GRS & NL & NL & ni & 4 \\
\hline Tan & SSI & NLL & NLcm & NL & $\mathrm{NL}$ & SSI & 1 \\
\hline Afg & SSI & NLL & NLcm & NL & NL & SSI & 1 \\
\hline Jul & SSI & NLL & NL & NL & NL & SSI & 1 \\
\hline A20 & SSI & NLL & CSnc, Y, Stu, GRS & NL & NL & SSI & 4 \\
\hline Pon & SSI & NLL & CSnc, Y, Stu, GRS & NL & NL & ni & 4 \\
\hline Sro & SSI & NLL & $\mathrm{NL}$ & NL & NL & SSI & 1 \\
\hline TamMV & SSI & NLL & ni & ni & NL & ni & 3 \\
\hline
\end{tabular}

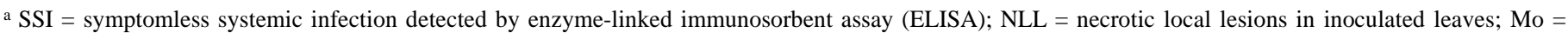
mottle symptoms; NL = necrotic lesions in top leaves that contained PVA titers detectable by ELISA; NLcm = all lesions were necrotic but contained chlorotic margins; $\mathrm{Y}=$ yellowing of leaves; CSnc = chlorotic lesions, in some of which the center necrotized after 2 to 4 days; GRS = green ringspots in nonnecrotic leaves that had turned yellow; Stu = stunting; and ni = no symptoms observed and no PVA detected by ELISA. 
potato genotypes have been selected as hosts having differential reactions to different strain groups of PVA, PVX, and PVY (45). Pathogen-free in vitro plantlets of these potato cultivars were transferred from tissue culture to the greenhouse, planted in soil, and multiplied for experiments by taking shoot cuttings. Plants were grown in the greenhouse under natural daylight supplemented with the illumination of sodium halide lamps. The daily means of the maximum and minimum temperatures were 23 and $19^{\circ} \mathrm{C}$, respectively.

Two Carborundum-dusted, fully expanded leaves of 'A6' plants (S. demissum $\times S$. tuberosum cv. Aquila) (15) were mechanically inoculated (47) using sap extracted from PVA-infected propagation host plants (Table 1). Development of necrotic local lesions was monitored for up to 10 days after inoculation (dpi). Side-graft inoculation using an apical shoot of a PVA-infected potato or tobacco plant was carried out as previously described (47). In all experiments, three plants of each test plant species and genotype were inoculated with each virus isolate, and each of these experiments were carried out two to three times. Symptom development was monitored in the graft-inoculated potato plants for up to 28 days, and plants were tested for PVA by DAS-ELISA at 21 and $28 \mathrm{dpi}$.

Virus detection. Detection of PVA in potato and tobacco plants was carried out using anti-PVA PAb and AP-conjugated PAb (Boehringer $\mathrm{GmbH}$ ), and the anti-PVA MAbs and the AP-conjugated MAbs 58/0, 58/6, and 58/7 (Agden Diagnostic Systems, Ayr, United Kingdom) (9), in parallel DAS-ELISAs. Uppermost fully expanded leaves were sampled, weighed, and ground in ELISA extraction buffer (47) at $1 \mathrm{~g}$ per $3 \mathrm{ml}$. Two aliquots $(100 \mu \mathrm{l})$ were transferred into two wells of a microtiter plate (Greiner Laborteknik, Frickenhausen, Germany). Color reactions were developed using $p$-nitrophenyl phosphate as a substrate, and absorbances were recorded at $405 \mathrm{~nm}$ using a microtiter plate reader (Titertek Multiscan or Titertek Multiscan MCC/340; Labsystems, Espoo, Finland). ELISA absorbance values $\left(A_{405}\right)$ were regarded as positive if they were two times higher ( \pm standard deviation) than those of the healthy control plants (20). Means of the $A_{405}$ values were compared using analysis of variance. Plants that showed negative or borderline $A_{405}$ values were retested by mechanical inoculation to 'A6'. The abovementioned MAbs, PAbs to the PVA isolate Dat produced in rabbits (F. Rabenstein, unpublished data), and anti-mouse (Sigma Chemical Co., St. Louis) and anti-rabbit AP-conjugated PAbs (Promega Corp., Madison, WI) were used for detection of PVA CPs by Western analysis as previously described (44).

TABLE 4. Transmissibility of the potato A potyvirus isolates by Myzus persicae in Nicotiana occidentalis plants ${ }^{\mathrm{a}}$

\begin{tabular}{lcccc}
\hline & $\begin{array}{c}\text { CP N-terminal } \\
\text { amino acids } \\
\text { PVA isolate }\end{array}$ & \multicolumn{3}{c}{$\begin{array}{c}\text { No. of infected plants/ } \\
\text { No. of aphid-inoculated plants }\end{array}$} \\
\cline { 4 - 5 } & 5 to 7 & Exp. 1 & Exp. 2 & Exp. 3 \\
\hline B11 & DAS & $0 / 15$ & $0 / 10$ & $0 / 20$ \\
$716 / 12$ & DAS & $\ldots$ b & $0 / 10$ & $\ldots$ \\
Dat & DA $\underline{\underline{S}}$ & $0 / 15$ & $0 / 10$ & $0 / 10$ \\
Adv & DA $\underline{\underline{S}}$ & $0 / 15$ & $0 / 10$ & $0 / 10$ \\
Ali & DA & $0 / 15$ & $0 / 10$ & $0 / 10$ \\
Jul & DTG & $0 / 15$ & $0 / 10$ & $0 / 10$ \\
U & DAG & $5 / 10$ & $2 / 10$ & $8 / 10$ \\
M & DAG & $\ldots$ & $\ldots$ & $8 / 30$ \\
Can & DAG & $\ldots$ & $\ldots$ & $4 / 30$ \\
Pit & DAG & $2 / 10$ & $\ldots$ & $\ldots$ \\
Her & DAG & $7 / 10$ & $5 / 10$ & $\ldots$ \\
Lin & DAG & $9 / 15$ & $5 / 10$ & $3 / 10$ \\
Pen & DAG & $1 / 10$ & $2 / 10$ & $\ldots$ \\
Tan & DAG & $1 / 10$ & $2 / 10$ & $3 / 10$ \\
Pon & DAG & $4 / 10$ & $\ldots$ & $\ldots$ \\
Sro & DAG & $3 / 15$ & $3 / 10$ & $\ldots$ \\
\hline
\end{tabular}

${ }^{\text {a }}$ The amino acids 5 to 7 of the coat protein $(\mathrm{CP}) \mathrm{N}$-terminus are shown and the substitutions putatively associated with the loss of aphid transmissibility are indicated by underlined letters in the first six isolates

b $\ldots=$ not tested.
Virus transmission by aphids. Transmission of PVA isolates by aphids (Myzus persicae Sulz.) was carried out as previously described (2) at the Institute of Plant Breeding Research and Pathogen Diagnostics, Aschersleben, Germany. Aphids were fasted for $1 \mathrm{~h}$, placed on PVA-infected leaves of $N$. occidentalis for virus acquisition (15 to $30 \mathrm{~min}$ ), and 10 aphids were transferred to each of the 10 to 30 healthy $N$. occidentalis plants in three independent experiments. PVA was detected in inoculated plants using the PAb and AP-conjugated PAb to PVA (Boehringer $\mathrm{GmbH}$ ) in DASELISA or plate-trapped antigen ELISA as previously described (37) at 14 and $21 \mathrm{dpi}$.

Cloning and sequencing of the HC, CP, and $3^{\prime}$ NTR sequences. Total RNA was extracted from PVA-infected tobacco or potato leaves, and the regions of PVA containing the HC-encoding sequence and the $\mathrm{CP}$-encoding and $3^{\prime} \mathrm{NTR}$ sequences were amplified by reverse transcriptase-polymerase chain reaction (RT-PCR) and cloned as previously described (47). The DNA polymerase Dynazyme (Finnzymes Oy, Espoo, Finland) was used, which, according to the manufacturer, has a twofold lower error rate than the DNA polymerase Taq. The oligonucleotide primers were designed according to the genomic sequence of the PVA isolate B11 (35) (Table 1). Primer 1 (5'-GGGATCCGTTATTCAACAGGGGATGTTTTC-3') corresponded to the $5^{\prime}$ end (nt 1,055 to 1,074) of PVA$\mathrm{B} 11 \mathrm{HC}$, and primer 2 (5'-CGTCGACTTATCCAACCCTGTAGTGCTTCA-3') was complementary to the $3^{\prime}$ end (nt 2,407 to 2,426) of the PVA-B11 HC (both primers contained adaptor sequences that are underlined). The $195^{\prime}$-end and $3^{\prime}$-end nt of the HC-encoding region were determined by sequencing other overlapping RTPCR-amplified cDNA clones (A. Merits, unpublished data). The $\mathrm{CP}$-encoding and $3^{\prime} \mathrm{NTR}$ sequences were amplified using primer 3 (5'-GTACTGAACTGGAAAAGTACT-3'; nt 8,458 to 8,478), which is designed upstream of the CP (nt 8,532 to 9,338), and primer 4 (5'-CCCTGACAGTTGAAACATAA-3'), which is complementary to the $3^{\prime}$ end of the $3^{\prime}$ NTR (nt 9,565 to 9,546; these nt have been shown to be identical in the eight previously sequenced PVA 3'NTRs) (4). Amplified cDNA fragments were separated by electrophoresis, isolated from the agarose gel using the Wizard PCR Preps DNA Purification System (Promega Corp.), and cloned using the pGEM-T Vector System (Promega Corp.). Both strands of two independent cDNA clones from each PVA isolate were sequenced using the AutoRead Kit (Pharmacia Biotechnology Inc., Uppsala, Sweden). A third clone was sequenced if the first two clones differed for any nt. Sequencing reactions were analyzed on an automated A.L.F. Express DNA Sequencer (Pharmacia Biotechnology Inc.).

Sequence analyses were carried out using the computer programs of the Wisconsin package version 8 (Genetics Computer Group, Madison, WI). Phylogenetic trees were constructed using the neighbor-joining method, and the significance of branch order was tested by 1,000 replications of bootstrap resampling of the original nt sequence alignments by Clustal $\mathrm{W}$ as previously described (51) and the aa sequence alignments by the PROTDIST (Dayhoff PAM matrix) and NEIGHBOR programs of the PHYLIP package version 35C (19).

Mutagenesis and expression of PVA CP in Escherichia coli. Arginine was substituted by lysine (R34K) in the CP of PVA isolate Her. Substitution was done in two independent CP cDNAs cloned into pGEM-T using the oligonucleotide 5'-AAATCGACATCTTTGTCCTTCACGG-3' and the USE Mutagenesis Kit (Pharmacia Biotechnology Inc.) according to the manufacturer's instructions. Mutated cDNAs were checked by sequencing. For expression in $E$. coli, two nonmutated and the two mutated cDNA clones were PCR-amplified using a primer corresponding to the $5^{\prime}$ end $\left(5^{\prime}\right.$ GGGATCCATGGCCGGAACTCTTGATGCAGGCG-3') and complementary to the $3^{\prime}$ end (5'-GGGTACCCTTCGGTTACACCCCCTTCACGCC-3') of the CP-encoding sequence of Her and including a Bam $\mathrm{HI}$ and $\mathrm{KpnI}$ restriction site, respectively (underlined). Amplification products were cloned into the plasmid pQE30 
and transformed into the E. coli strain M15 pREP4+ (Qiagen, Hilden, Germany). Bacteria were grown under shaking at $37^{\circ} \mathrm{C}$ until an optical density value of 0.6 (at $600 \mathrm{~nm}$ ) was reached and $2 \mathrm{mM}$ isopropyl-thio- $\beta$-D-galactoside was added for the induction of protein expression. Culturing was continued for $5 \mathrm{~h}$ at $28^{\circ} \mathrm{C}$. Cells were resuspended in $50 \mathrm{mM}$ sodium phosphate buffer $(\mathrm{pH} 8.0)$ containing $300 \mathrm{mM} \mathrm{NaCl}$ and broken using a French press (10,000 psi; SLM Instruments Inc., Urbana, IL). The lysate was fractioned by centrifugation at $15,000 \times g$ for $30 \mathrm{~min}$. The supernatant was analyzed using SDS-PAGE, Western analysis, and DAS-ELISA as described above.

\section{RESULTS}

Host plant responses. All 21 PVA isolates included in this study had the capacity to infect tobacco plants systemically (Table 2). Usually no symptoms developed, but transient mild mosaic symptoms were occasionally observed with all isolates. The relative virus titers among isolates varied in different experiments based upon ELISA absorbance values, which was probably attributable to variability in environmental conditions and the growth stage of tobacco plants. However, a few isolates such as B11, $716 / 12$, and Dat had higher titers than some other isolates such as Pit, Her, Lin, A20, and Sro in the systemically infected tobacco leaves (Table 2).

All isolates caused the development of similar necrotic lesions characteristic to PVA (15) in the mechanically inoculated leaves of the potato hybrid 'A6' (Table 3), but no PVA was detected by ELISA. 'A6' is a sensitive PVA local lesion host that was commonly used for indexing PVA infections in potato before serological methods became available (15).

Capacity of the PVA isolates to induce necrotic lesions in potato cvs. King Edward, Maris Piper, and Pentland Dell and to infect
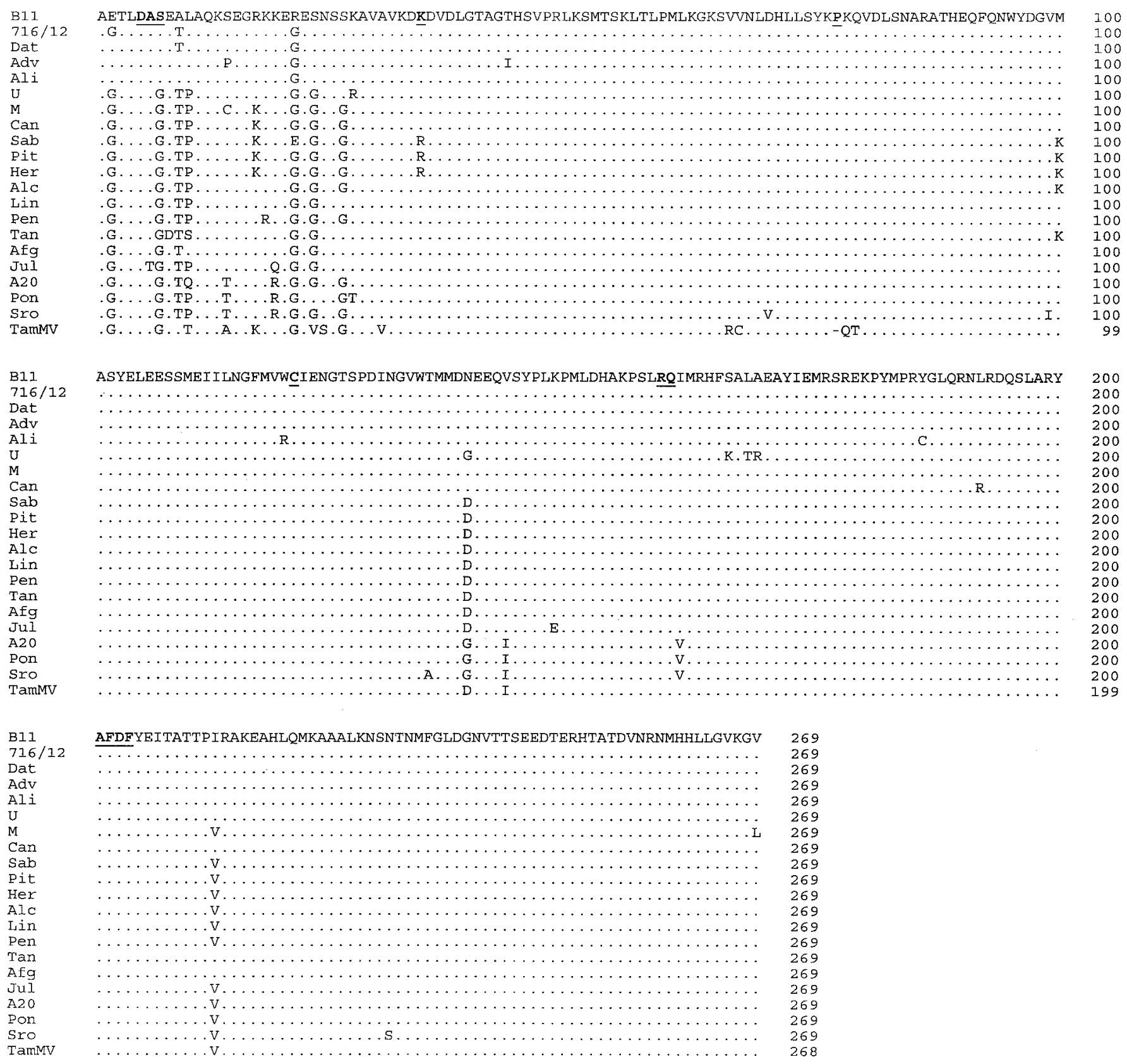

Fig. 1. Multiple alignment of the coat protein $(\mathrm{CP})$ amino acid sequences of 20 potato A potyvirus isolates relative to the isolate B11. Only the amino acids that differ from those of B11 are shown. Identical amino acids are indicated by dots. Deletions are indicated by dashes. The motif DAS/DAG involved in aphid transmissibility, the lysine $(\mathrm{K})$ residue crucial for the epitope of the MAb 58/0 and 58/7, the proline (P) residue lacking from TamMV CP, and the cysteine (C) residue and the motives RQ and AFDF conserved in all potyviruses (41) are bold and underlined in the B11 sequence. 
Pentland Ivory systemically was tested by side-graft inoculation, which was the method of inoculation used in the previous study that identified the three PVA strain groups (47). The responses to 12 isolates (716/12, Dat, U, Sab, Pit, Her, Alc, Lin, Tan, Afg, Jul, and Sro) were similar in that all caused necrotic lesions in the upper leaves of 'King Edward', and PVA was detected in the symptomatic leaves by ELISA 14 to 17 days after side-graft inoculation (Table 3). However, the isolates Her, Pit, Sab, Jul, and Sro caused necrotic lesions with sharp borders, similar to those previously reported in 'Maris Piper' after graft inoculation with PVA (47), but other isolates caused necrotic lesions that had chlorotic margins similar to those previously reported to be caused by PVA-U in 'King Edward' (47). Isolates Ali and M caused mottle symptoms in 'King Edward' at 14 to 17 dpi. Isolates Can, Pen, Pon, and A20 caused initially chlorotic lesions in the top leaves, and PVA was detected in these leaves by ELISA. The center of only a few lesions turned necrotic after 2 to 4 days. Infected plants became stunted and all leaves turned yellow 17 to $24 \mathrm{dpi}$, whereby in the lower, initially symptomless leaves, green ringspots became visible. No symptoms or infection detectable by ELISA were observed in 'King Edward' 28 dpi after side-graft inoculation with isolates B11, Adv, and TamMV.

All isolates caused necrotic lesions in the upper leaves of 'Maris Piper', except isolates B11, Adv, M, and TamMV, which caused no symptoms and no infection detectable by ELISA in the upper leaves at 28 dpi (Table 3). All isolates caused necrotic lesions in the upper leaves of 'Pentland Dell', except isolates B11 and Adv, which caused no symptoms and no detectable infection at 28 dpi. All PVA isolates that caused necrotic lesions in 'Maris Piper' and 'Pentland Dell' were detected by ELISA in at least one, but not all, of the six to nine tested leaves that had necrotic lesions. Many isolates (Table 3) caused a systemic symptomless infection detectable by ELISA in the upper leaves of 'Pentland Ivory', but no virus was detected by ELISA and no symptoms were observed with isolates B11, 716/12, Ali, Pen, Pon, and TamMV at 28 dpi (Table 3).
Transmissibility by aphids. Of the 16 PVA isolates tested, 10 isolates (U, M, Can, Pit, Her, Lin, Pen, Tan, Pon, and Sro) were transmitted by Myzus persicae (Table 4). They contained the DAG aa motif at the CP N-terminus (aa positions 5 to 7) (Fig. 1). The isolates B11, 716/12, Dat, Adv, and Ali contained the aa substitution G7S and isolate Jul contained the substitution A6T in this motif (Fig. 1), and they were not transmitted by aphids (Table 4).

CP sequences. The entire $\mathrm{CP}$ nt sequences and deduced aa sequences of 10 new PVA isolates (716/12, Afg, Alc, A20, Her, Pen, Pit, Pon, Sab, and Tan) and 3 PVA isolates (Adv, Dat, and Lin) previously characterized only for their CP N-terminus (3) (Table 1) were determined in this study. The nt sequences were deposited to and are available from the EMBL Nucleotide Sequence Database, and the accession numbers are shown in Table 1.

Alignment of the deduced CP aa sequences (Fig. 1) of the abovementioned isolates, along with the previously reported complete CP sequences of six PVA isolates (Can, M, U, Ali, Jul, and Sro) (Table 1) and TamMV $(3,18)$, was made relative to the CP-encoding region of B11-icDNA (36). The CP of B11-icDNA (Fig. 1) contains three aa substitutions (Q18R, G21R, and G26S) as compared with the previously published CP sequence of PVA-B11 (34, $35,47)$. The length of the CP was 269 aa in all PVA isolates except TamMV, which lacks a proline residue at position $77(18,34)$. In all PVA isolates, the first aa residue of the $\mathrm{CP}$ was alanine, as reported for many potyviruses (41). Of the first $34 \mathrm{~N}$-terminal aa positions, 17 contained aa changes (Fig. 1). In other parts of the $\mathrm{CP}, 22$ positions contained aa changes. In 17 of these positions, the change had occurred only in a single isolate (Fig. 1). The overall CP aa sequence identity was $92.9 \%$.

Phylogenetic analysis of the complete CP aa sequences (Fig. 2) or nt sequences (data not shown) resulted in similar clustering of the PVA isolates. Isolates 716/12, Dat, B11, Ali, and Adv were quite similar to each other (identity 98.5 and $98.8 \%$ at the nt and aa sequence level, respectively) and were placed in a distant cluster (Fig. 2). These five isolates contained a substitution of glycine by serine $(\mathrm{G} 7 \mathrm{~S})$ in the DAG motif required for aphid transmissi-

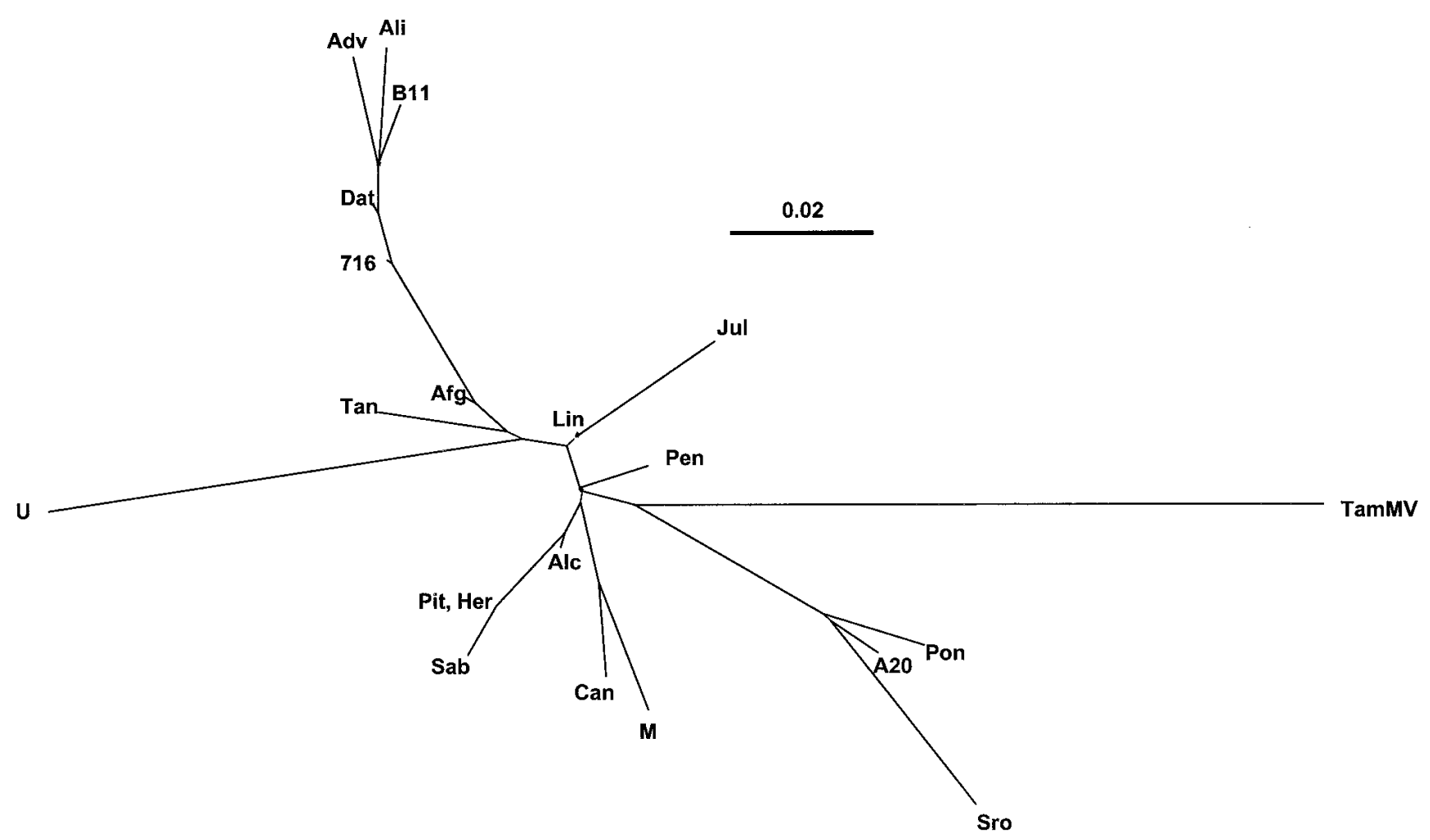

Fig. 2. Clustering by PHYLIP (19) of the potato A potyvirus coat protein amino acid sequences. The bar represents 0.02 Dayhoff PAM matrix units (19). 
bility of potyviruses $(6,23,25)$. Four of these isolates $(716 / 12$, Dat, Ali, and Adv) were isolated in Braunschweig, Germany, whereas B11 was obtained from Hungary. They formed a cluster that showed the closest relation to isolates Afg, Jul, Lin (the Netherlands), Tan (Finland), and U (Wisconsin) (Fig. 2). Isolates M (Maine) and Can (Fredericton) clustered together (identity 99.3 and $98.5 \%$ at the nt and aa sequence level, respectively). The three Finnish isolates (Her, Pit, and Sab) were very similar (identity $99.6 \%$ at the nt and aa sequence level) and closely related to the isolates Alc (the Netherlands) and Pen (Scotland, United Kingdom). Isolates A20, Pon (Scotland, United Kingdom), and Sro (the Netherlands) formed one cluster. Isolate TamMV (New Zealand; natural host tamarillo) clustered separately from all other isolates (Fig. 2).

All PVA CPs contained aa residues conserved in potyvirus CPs, including a cysteine residue at aa position 121 (41) and the arginine and aspartic acid residues at positions 159 and 203, respectively, of the sequences RQ and $\operatorname{AFDF}(16,28)$ (Fig. 1).

HC sequences. The HC-encoding sequences were determined in nine PVA isolates (Adv, Ali, Can, M, Her, Jul, U, Sro, and TamMV), which represented the main clusters formed based on the $\mathrm{CP}$ sequences (Fig. 2). The deduced $\mathrm{HC}$ aa sequences were aligned relative to the previously reported $\mathrm{HC}$ sequence of isolate B11 (35) (Fig. 3). The EMBL Nucleotide Sequence Database accession numbers of the HC sequences are Z21670 (B11), Y14860 (Ali), and Y14121 to Y14128 (other PVA isolates).

The length of the HC was 458 aa in all PVA isolates (Fig. 3). The overall $\mathrm{HC}$ aa sequence identity was $94.8 \%$, which was $1.9 \%$ higher than for the $\mathrm{CP}$ aa sequences. No $\mathrm{HC}$ aa sequence was identical to any other isolate, but in two cases, only one aa difference was found between two PVA isolates (B11 versus Adv, and $\mathrm{U}$ versus Can) (Fig. 3). The aa residues conserved in the HCs of other potyviruses and known to be significant for the biological functions of HC (32) were conserved in the PVA HCs (Fig. 3). Substitution of the histidine or cysteine residues corresponding to the PVA $\mathrm{HC}$ aa $\mathrm{H}^{25}, \mathrm{C}^{27}$, and $\mathrm{C}^{55}$ are known to be lethal to other potyviruses (32). The conserved cysteine and lysine residues corresponding to the PVA $\mathrm{HC}$ aa 36 and 52, respectively, and the variable aa residues corresponding to PVA $\mathrm{HC}$ aa $\mathrm{S}^{28}$ and $\mathrm{S}^{29}$, affect accumulation and symptom expression (5). The lysine residue corresponding to PVA HC aa 52 and the conserved motif PTK corresponding to the PVA HC aa 310 to 312 are required for aphid transmissibility (27). The conserved IGN motif of the LAIGN box
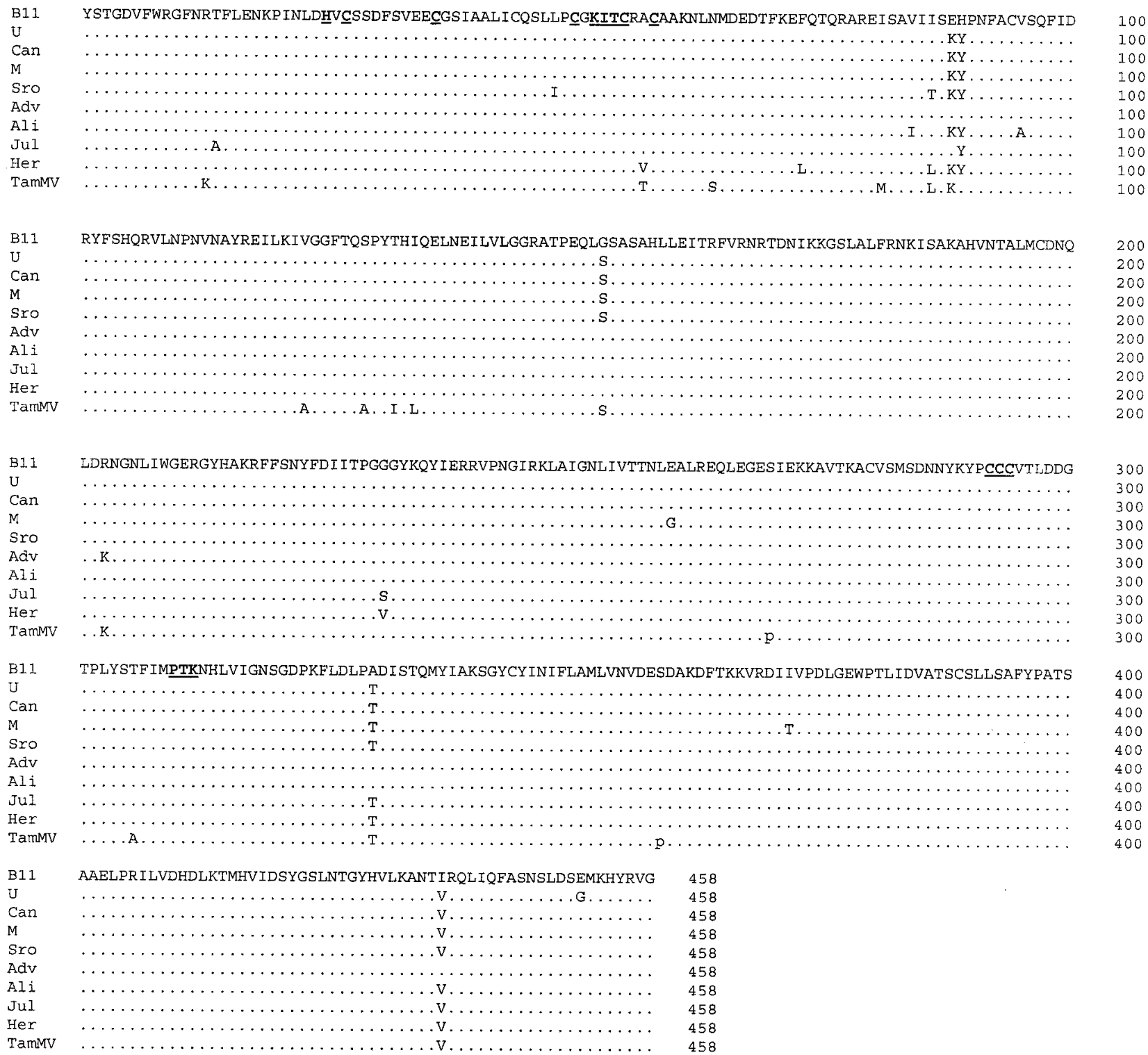

Fig. 3. Multiple alignment of the helper component proteinase (HC) amino acid sequences of nine potato A potyvirus isolates relative to the isolate B11. Only the amino acids that differ from those of B11 are shown. Identical amino acids are indicated by dots. Histidine (H) and cysteine (C) residues and other motifs conserved in potyvirus HCs are underlined (more detailed explanation in text). 
(PVA HC aa 244 to 248) is involved in the cell-to-cell and long-distance movement of tobacco etch potyvirus (TEV), whereas the conserved CCC motif corresponding to the PVA HC aa 292 to 294 is needed for the systemic movement of TEV (14). In yam mosaic potyvirus (YMV), another LAIGN box is found 63 aa downstream from the first one (1), whereas in PVA HC, a LVIGN box was found 67 aa downstream from the LAIGN box. In the six PVY isolates available in the EMBL database (D00441, M95491, Z50041 to Z50043, and X97895), the first IGN motif is found in a LAIGN (two isolates) or LSIGN box (four isolates), but the second motif is in a LVIGN box in all six isolates. Significance of the second IGN motif is not known. The cysteine residue corresponding to PVA $\mathrm{HC}$ aa $\mathrm{C}^{58}$ is conserved in potyviruses, but its significance is unknown (32).

The clusters of the PVA HC aa sequences identified by phylogenetic analysis (data not shown) were largely consistent with the main clusters identified based on the $\mathrm{CP}$ aa sequences.

3'NTR sequences. The 3'NTR sequences of the 13 above-mentioned PVA isolates were determined (Fig. 4; Table 1 shows EMBL
Nucleotide Sequence Database accession numbers). Ten isolates (B11, U, 716/12, Adv, Dat, Ali, Afg, Lin, Jul, and Tan) differed from the other eleven isolates (M, Can, Sab, Pit, Her, Alc, Pen, A20, Pon, Sro, and TamMV) in that the 3'NTRs of the former group lacked nt 26 and nt 27 (T and A, respectively) (Fig. 4). These two groups were consistent with the two main clusters (data not shown) identified by the phylogenetic analysis that ignored the alignment positions that contained a gap. The $3^{\prime}$ NTRs of the former group were very similar and contained a maximum of three nucleotide differences, whereas the $3^{\prime} \mathrm{NTR}$ of the second group of PVA isolates were more variable and contained up to $21 \mathrm{nt}$ differences (Fig. 4). When the presence or absence of nt 26 and nt 27 was ignored, the overall $3^{\prime}$ NTR sequence identity was $93.4 \%$.

Serological properties. All PVA isolates of this study were detected in infected tobacco leaves with the PAb (Boehringer $\mathrm{GmbH}$ ) and ELISA (Table 2). All PVA isolates, except isolates Her, Pit and Sab, were also detected by ELISA (Table 2) and Western analysis (data not shown) with MAb 58/0 and 58/7. In contrast, MAb

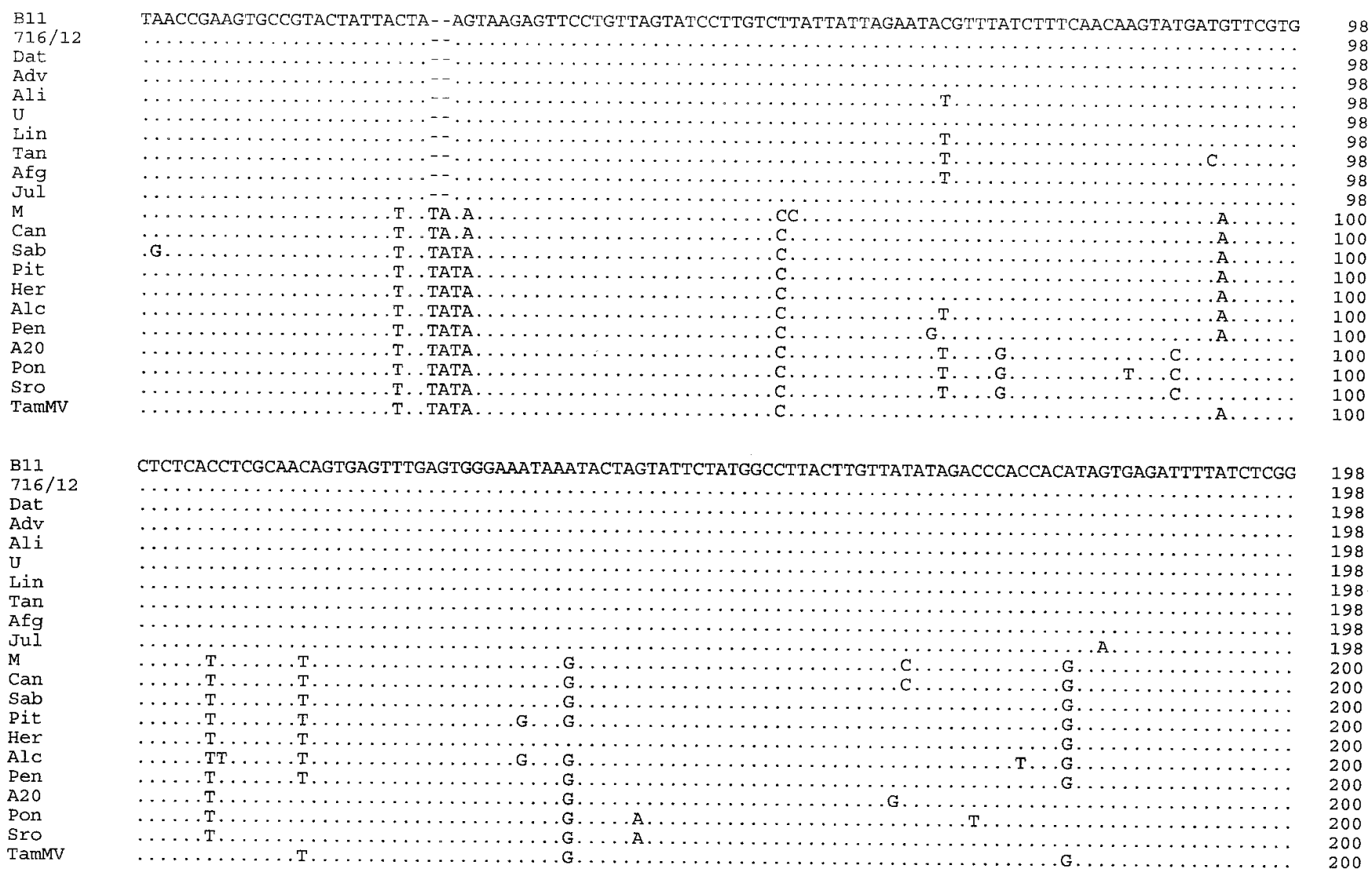

\begin{tabular}{|c|c|c|}
\hline B11 & TGACTGGTTTTATGTTTCAACTGTCAGGG & 227 \\
\hline $716 / 12$ & $\ldots \ldots \ldots$ & 207 \\
\hline Dat & $\ldots \ldots \ldots$ & 207 \\
\hline Adv & $\ldots \ldots \ldots$ & 207 \\
\hline Ali & $\ldots \ldots \ldots \ldots \ldots \ldots \ldots \ldots \ldots \ldots$ & 227 \\
\hline U & $\cdots \cdots \cdots$ & 207 \\
\hline Lin & $\cdots \ldots \ldots$ & 207 \\
\hline $\operatorname{Tan}$ & $\ldots \ldots$ & 207 \\
\hline Afg & $\cdots \cdots \cdots$ & 207 \\
\hline Jul & $\cdots \ldots \ldots$ & 227 \\
\hline $\mathrm{M}$ & . A $\ldots$. . & 209 \\
\hline Can & . A..... & 229 \\
\hline Sab & $\cdots G A \ldots$ & 209 \\
\hline Pit & $\ldots$ GA. . . . & 209 \\
\hline Her & . GA.... & 209 \\
\hline Alc & . A.... & 209 \\
\hline Pen & $\cdots$ A.... & 209 \\
\hline A20 & ....... & 209 \\
\hline Pon & $\cdots$ A.... & 209 \\
\hline Sro & $\cdots A \ldots \ldots \ldots \ldots$ & 229 \\
\hline TamMV & $\ldots$ A....... & 229 \\
\hline
\end{tabular}

Fig. 4. Multiple alignment of the $3^{\prime}$-end nontranslated region nucleotide sequences of 20 potato A potyvirus isolates relative to the isolate B11. Only the nucleotides that differ from B11 are indicated. 
58/6 detected 9 out of 18 PVA isolates (U, Can, Sab, Pit, Her, Lin, Pen, Jul, and Pon). Thus, MAb 58/0 (or MAb 58/7, which recognized the same epitope as MAb 58/0; described below) and 58/6 could be used to identify three groups of PVA isolates: group 1 containing isolates U, Can, Lin, Pen, Jul, and Pon recognized by both MAbs; group 2 containing isolates B11, 716/12, Dat, Adv, Ali, Tan, A20, Sro, and TamMV recognized by MAb 58/0 but not by MAb 58/6; and group 3 containing isolates Her, Pit, and Sab recognized by MAb 58/6 but not by MAb 58/0. This was also consistent with testing up to $500 \mathrm{ng}$ of purified virions of isolates B11, U, and Sab with the three MAbs by DAS-ELISA (Table 5).

Comparison of the $\mathrm{CP}$ aa sequences showed that isolates Her, Pit, and Sab differed from all other isolates by having arginine (R) instead of lysine $(\mathrm{K})$ at aa position 34 of the $\mathrm{CP}$ (Fig. 1). To test the potential significance of this aa substitution, the $\mathrm{R}$ was changed to $\mathrm{K}(\mathrm{R} 34 \mathrm{~K})$ by point mutation in two cDNA clones of the Her CP. Both wild-type and mutated CPs were then expressed in $E$. coli as 6xHis-tag fusion proteins. The ability of the CP to assemble into particles was apparently not affected by this mutation, since PVA-like particles were observed in E. coli expressing the mutated $\mathrm{CP}$ (data not shown). CP concentrations in the bacterial lysates were determined using SDS-PAGE, and serial dilutions of lysates were tested in parallel with the PAb and MAbs by DAS-ELISA. As expected, the nonmutated CP was not detected with MAb 58/0 and 58/7, whereas it was readily detected with MAb 58/6. In contrast, the mutant $\mathrm{CP}$ was readily detected with the PAb and all MAbs (Table 5). Similarly, the mutated CP but not the wild-type $\mathrm{CP}$ of Her was detected by MAb 58/0 (Fig. 5) and MAb 58/7 using Western blot analysis. These data indicated that MAbs 58/0 and 58/7 recognized the same epitope, which was linear rather than conformational. The epitope of MAb 58/6 was not determined by site-directed mutagenesis, but the proline $(\mathrm{P})$ at $\mathrm{CP}$ aa position 10 may be crucial for it, because isolates that did not contain $\mathrm{P}$ at this aa position were not detected by MAb 58/6 (Fig. 1; Tables 2 and 5). Other aa changes in CPs did not correlate with recognition by MAb 58/6. The epitopes recognized by the three MAbs were not significantly degraded during storage of PVA virions in phosphate buffer $\left(\mathrm{pH} \mathrm{7.4)}\right.$ at $4{ }^{\circ} \mathrm{C}$ for 18 months, because similar amounts of newly purified virions gave similar absorbance values (data not shown).

\section{DISCUSSION}

The 21 PVA isolates of this study differed in their biological properties, such as virulence (defined as the measure of pathogenicity) (49) and capacity to cause necrotic lesions in potato $\mathrm{cv}$. King Edward, systemic spread in four potato cultivars, transmission by aphids, and also in their serological properties. The CP aa

TABLE 5. Mean enzyme-linked immunosorbent assay (ELISA) absorbance values $^{\mathrm{a}}$ for purified potato A potyvirus (PVA) virions or PVA coat protein $(\mathrm{CP})^{\mathrm{b}}$

\begin{tabular}{llccc}
\hline PVA isolate & Antigen & MAb 58/0 & MAb 58/6 & MAb 58/7 \\
\hline B11 & Virions & 3.36 & 0.01 & 3.42 \\
$\mathrm{U}$ & Virions & 3.12 & 3.99 & 3.99 \\
$\mathrm{Sab}$ & Virions & 0.01 & 3.53 & 0.04 \\
$\mathrm{Her}$ & $\mathrm{CP}$ & 0.06 & 2.93 & 0.07 \\
$\mathrm{Her}(\mathrm{R} 34 \mathrm{~K}){ }^{\mathrm{c}}$ & $\mathrm{CP}$ & 2.82 & 1.68 & 2.91 \\
Dat & $\mathrm{CP}$ & 3.13 & 0.01 & 3.08 \\
Control & Buffer & 0.00 & 0.00 & 0.00 \\
Control & E. coli lysates $^{\mathrm{d}}$ & 0.05 & 0.02 & 0.06 \\
\hline
\end{tabular}

a Means of a total of four readings for $500 \mathrm{ng}$ of purified virus or coat protein. Purified PVA virions or PVA CP expressed in Escherichia coli detected by monoclonal antibodies (MAb) using double-antibody sandwich-ELISA in two independent experiments $\left(\mathrm{LSD}_{0.05}=0.27\right)$.

c Arginine (R) at the amino acid position 34 changed to lysine $(\mathrm{K})$ in Her CP by directed mutagenesis. Also, isolate $\mathrm{Sab}$ has $\mathrm{R}$ at this amino acid position, whereas isolates B11, $\mathrm{U}$, and Dat have K.

${ }^{\mathrm{d}}$ Lysates of E. coli strain containing the noninduced plasmid pQE30. sequence identity $(\geq 92.9 \%)$ of these virus isolates indicated that all were PVA, because the $\mathrm{CP}$ aa sequence identity among potyvirus isolates and between different potyviruses is $>90 \%$ and $<70 \%$, respectively $(1,41)$. For example, $21 \mathrm{PVY}$ isolates from different host species and geographic areas show a $\mathrm{CP}$ aa sequence identity (48). Amino acid sequence identity (94.8\%) of the PVA HCs (10 isolates) was comparable to the $\mathrm{HC}$ central region (153 aa; identity $94.1 \%$ ) in six YMV isolates (1), but was more conserved than the HC sequences of the six PVY isolates available from the EMBL database (identity $89.1 \%$ ). Because a polymerase with a low error rate was used, and each nt sequence consensus was determined based on comparison of at least two independent cDNA clones, it is plausible that most aa differences were authentic (42).

The 3'NTR sequences of PVA (identity 93.4\%) were more conserved than those reported for PVY isolates (identity 83.6\%) (48). The $3^{\prime} \mathrm{NTR}$ of tobacco vein mottling potyvirus (TVMV) affects symptom development (38), but the differences among the $3^{\prime} \mathrm{NTR}$ sequences of PVA did not correlate with the biological properties examined. However, it is intriguing that the $103^{\prime}$ NTRs that lacked nt 26 and nt 27 contained only up to three nt substitutions, whereas the other $113^{\prime} \mathrm{NTR}$ contained up to $21 \mathrm{nt}$ substitutions. A previous study has shown that the potyvirus $3^{\prime} \mathrm{NTR}$ is involved in the initiation of the minus-strand RNA synthesis (10) and secondary stem-loop structures have been predicted to exist in the $3^{\prime}$ NTR of PVY (48). Whether or not nt 26 and nt 27 of the PVA $3^{\prime}$ NTR are functionally significant and whether lack of them re-
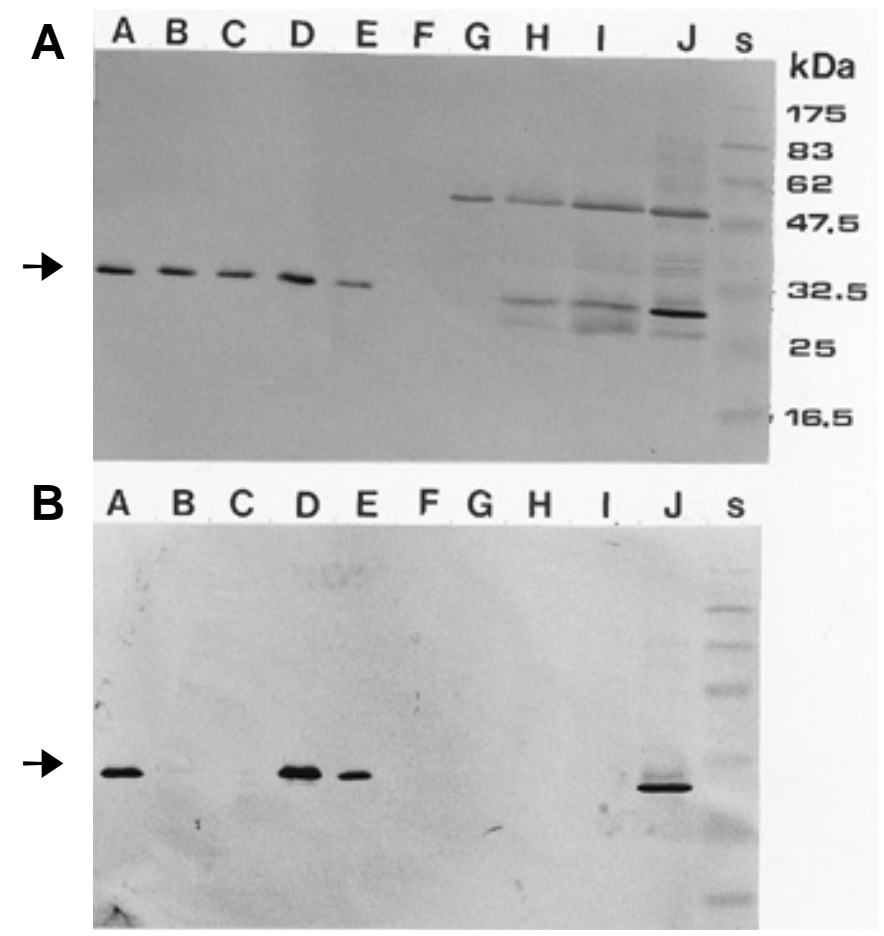

Fig. 5. Western immunoblot analysis of wild type and mutagenized potato A potyvirus (PVA) coat proteins (CPs). A, Blot was probed with polyclonal rabbit antibodies to PVA. B, Blot was probed with the monoclonal antibody 58/0 to PVA. Lanes A to E contained CPs synthesized in Escherichia coli. Lanes $\mathrm{H}$ to $\mathrm{J}$ contained CPs from PVA-infected tobacco plants 18 dpi. The position of PVA CP is indicated with an arrowhead. Additionally, the polyclonal antibody $(\mathrm{PAb})$ recognized a protein of approximately $50 \mathrm{kDa}$ in healthy (lane G) and PVA-infected (lanes $\mathrm{H}$ to $\mathrm{J}$ ) tobacco plants. Bands smaller than the $\mathrm{CP}$ and recognized by the PAb (lanes $\mathrm{H}$ to $\mathrm{J}$ ) probably represent degraded CP. Lane A, Dat; lanes B and C, nonmutagenized Her; lanes D and E, two independently mutagenized Her CPs containing the amino acid substitution R34K; lane F, lysate prepared from E. coli transformed with the plasmid pQE30 but in which CP expression was not induced; lane G, healthy tobacco; lane H, Her; lane I, Pit; lane J, Ali; lane s, prestained protein marker (New England Biolabs, Hitchin, United Kingdom) with molecular masses (in $\mathrm{kDa}$ ) as indicated in $\mathbf{A}$. 
stricts the extent to which the nucleotides at other positions can vary remains to be studied.

The clusters of PVA isolates based on the phylogenetic analysis of CP (and HC and 3'NTR) sequences were only partially consistent with the geographic areas from which the isolates were obtained for this study. This may be attributable to dispersal of PVA via the trade of potato tubers, as is the case with the dispersal of YMV in yam according to a previous study (1).

TamMV (18) was originally isolated from tamarillo (C. betacea; recently renamed $S$. betaceum) (8) and its ability to infect potato plants has not been reported. This study showed that TamMV has the capacity to induce necrotic lesions identical to those induced by other PVA isolates in the mechanically inoculated leaves of 'A6'. Systemic spread of TamMV was observed only in potato cv. Pentland Dell, which developed a few necrotic lesions in the upper leaves following side-graft inoculation. Indeed, adaptation to and natural occurrence in different host species seems to have been the major reason to consider TamMV and PVA as different viruses in the past (18). Comparison of the $\mathrm{CP}$ and $\mathrm{HC}$ aa sequences, and the $3^{\prime} \mathrm{NTR}$ sequence in particular, supports the previous suggestion (3) that TamMV is a strain of PVA. Furthermore, similar to other PVA isolates, TamMV was detected with the PVA-specific PAb and MAbs 58/0 and 58/7.

Capacity to spread systemically and induce necrotic lesions, mottle symptoms, or no systemic infection in 'King Edward' following side-graft inoculation are the originally used criteria to place PVA isolates into three strain groups (47). Therefore, sidegraft inoculation rather than mechanical inoculation of the potato cultivars was carried out also in this study. Twelve isolates that caused distinct necrotic lesions, with or without chlorotic margins, in the upper leaves of 'King Edward' were placed into PVA strain group 1. Isolates Ali and $\mathrm{M}$, which caused mottle symptoms and no necrosis, were placed into strain group 2. Isolates B11, Adv, and TamMV, which caused no symptoms and were not detected by ELISA in the upper leaves of 'King Edward', were placed into strain group 3. However, the response of 'King Edward' to infection with isolates Can, Pen, Pon, and A20 was different from the above-mentioned three groups of PVA isolates (Table 3). Therefore, a new strain group (group 4) is proposed for these isolates, which cause stunting and yellowing in 'King Edward'. Comparisons of the CP, $3^{\prime} \mathrm{NTR}$, and HC sequences of the four PVA strain groups revealed no aa or nt change that correlated with the loss of capacity to induce necrosis in 'King Edward'. Similarly, no aa or nt substitution was common for the isolates of strain group 4 and different from other strain groups, which suggested that none of them, at least alone, determined the type of symptoms induced in 'King Edward'. In TVMV, 3'NTR and the N-terminal part of HC are known to affect symptom severity in certain host species $(4,38)$. Lack of systemic infection in the potato cultivars was not correlated with the differences in the PVA $\mathrm{CP}, \mathrm{HC}$, or 3'NTR sequences. In contrast to the different responses to different strain groups in 'King Edward', all PVA isolates that spread systemically in 'Maris Piper' and 'Pentland Dell' induced systemic necrosis in these cultivars, and all isolates activated the gene for HR to PVA in potato hybrid 'A6'.

Aphid-transmissible isolates of PVA contained the DAG motif at the CP N-terminus, which is similar to other aphid-transmissible potyviruses $(6,23,25)$, whereas the loss of aphid transmissibility in PVA was correlated with the single aa change G7S in isolates Adv, Ali, B11, Dat, and 716/12, and with the aa change A6T in isolate Jul. The HC sequences of four non-aphid-transmissible PVA isolates (Adv, Ali, B11, and Jul) were analyzed, and all contained the conserved $\mathrm{HC}$ aa domains needed for potyvirus transmission by aphids (32), which was consistent with the single aa substitution in the $\mathrm{CP}$ being responsible for the loss of aphid transmissibility. On the other hand, the aa substitution G7S and loss of aphid transmissibility coincided with the five PVA isolates (716/12, Adv, Ali, Dat, and B11) that had highly identical CP aa sequences
(98.8\%). As four of these isolates were reportedly isolated at BBA Braunschweig, Braunschweig, Germany, and the origin of isolate B11 obtained from Hungary is not clear, the possibility remains that they all have a common geographic origin, providing an explanation for the high CP identity. On the other hand, all five isolates have in common that they have been maintained in Nicotiana spp. through many passages by mechanical inoculation, which may have contributed to changes in genomic sequences and biological properties. Repeated mechanical transmission of aphid-transmissible strains of potyviruses can abolish aphid transmissibility (30, 41 ), and repeated propagation of some viruses, such as PVX, in test plant species can reduce the ability of the virus strain to infect the natural host from which the virus was originally isolated (33).

The CP N-terminus of potyviruses is variable and is the immunodominant region $(2,40)$. Therefore, it was not unexpected to find the epitopes corresponding to MAbs 58/0,58/7, and 58/6 within this region. None of these MAbs recognize all of the PVA isolates used in this study, but they are useful for detection of PVA because of their high sensitivity in DAS-ELISA $(9,46)$. However, the epitopes detected by these three MAbs did not correlate with any biological properties examined in this study and, therefore, the groups of isolates formed based on the biological and serological properties were different.

\section{ACKNOWLEDGMENTS}

This work was financially supported by The Academy of Finland (grants 6997, 34529, and 36256 to J. P. T. Valkonen) and by fellowships to A. Merits from The Nordic Council of Ministers and to J. Andrejeva from the Center of International Mobility (CIMO) and Estonian Science Foundation (grant 2297). We thank I. A. Browning for providing potato A potyvirus (PVA) isolates and monoclonal antibodies to PVA and potato $\mathrm{V}$ potyvirus; J. F. J. M. van den Heuvel, R. P. Singh, and J. P. Palohuhta for providing PVA isolates; H. L. Weidemann for information about the origin of PVA isolates Adv, Ali, and Dat; S. Schaffer for information about the maintenance of PVA type strain 716/12 at ATCC; and K. Mäkinen, D. Guo, and M. Saarma for critical review of an earlier version of the manuscript.

\section{LITERATURE CITED}

1. Aleman-Verdaguer, M.-E., Goudou-Urbino, C., Dubern, J., Beachy, R. N., and Fauquet, C. 1997. Analysis of the sequence diversity of the P1, $\mathrm{HC}, \mathrm{P} 3, \mathrm{NIb}$ and $\mathrm{CP}$ genomic regions of several yam mosaic potyvirus isolates: Implications for the intraspecific molecular diversity of potyviruses. J. Gen. Virol. 78:1253-1264.

2. Andreeva, L., Järvekülg, L., Rabenstein, F., Torrance, L., Harrison, B. D., and Saarma, M. 1994. Antigenic analysis of potato virus A particles and coat proteins. Ann. Appl. Biol. 125:337-348.

3. Andrejeva, J., Merits, A., Rabenstein, F., Puurand, Ü., and Järvekülg, L. 1996. Comparison of the nucleotide sequences of the 3 '-terminal regions of one aphid and two non-aphid transmissible isolates of potato A potyvirus. Arch. Virol. 141:1207-1219.

4. Atreya, C. D., Atreya, P. L., Thornbury, D. W., and Pirone, T. P. 1992. Site-directed mutations in the potyvirus HC-PRO gene affect helper component activity, virus accumulation, and symptom expression in infected tobacco plants. Virology 191:106-111.

5. Atreya, C. D., and Pirone, T. P. 1993. Mutational analysis of the helper component-proteinase gene of a potyvirus: Effect of amino acid substitutions, deletions and gene replacement on virulence and aphid transmissibility. Proc. Natl. Acad. Sci. U.S.A. 90:11919-11923.

6. Atreya, C. D., Raccah, B., and Pirone, T. P. 1990. A point mutation in the coat protein abolishes aphid transmissibility of a potyvirus. Virology 178:161-165.

7. Bartels, R. 1971. Potato Virus A. CMI/AAB Descriptions of Plant Viruses 54. Commonw. Mycol. Inst./Assoc. Appl. Biol., Surrey, United Kingdom.

8. Bohs, L. 1995. Transfer of Cyphomandra (Solanaceae) and its species to Solanum. Taxon 44:583-587.

9. Browning, I. A., Burns, R., George, E. L., and Darling, M. 1995. Development and evaluation of ELISA assays incorporating monoclonal antibodies for the detection of potato A potyvirus. EPPO (Eur. Plant Prot. Organ.) Bull. 25:259-268.

10. Bryan, G. T., Gardner, R. C., and Forster, R. L. S. 1992. Nucleotide 
sequence of the coat protein gene of a strain of clover yellow vein virus from New Zealand: Conservation of a stem-loop structure in the 3' region of potyviruses. Arch. Virol. 124:133-146.

11. Calvert, E. L. 1960. Potato virus A in the variety Ulster Torch. Plant Pathol. 9:144-146.

12. Clark, M. F., and Adams, A. N. 1977. Characteristics of the microplate method of enzyme-linked immunosorbent assay for the detection of plant viruses. J. Gen. Virol. 34:475-483.

13. Collins, R. F., LecLerc, D., and AbouHaidar, M. G. 1993. Cloning and nucleotide sequence of the capsid protein and the nuclear inclusion protein $(\mathrm{NIb})$ of potato virus A. Arch. Virol. 128:135-142.

14. Cronin, S., Verchot, J., Haldeman-Cahill, R., Schaad, M. C., and Carrington, J. C. 1995. Long distance movement factor: A transport function of the potyvirus helper component proteinase. Plant Cell 7:549-559.

15. De Bokx, J. A. 1972. Test plants. Pages 102-127 in: Viruses of Potatoes and Seed-Potato Production. J. A. De Bokx, ed. Pudoc, Wageningen, the Netherlands.

16. Dolja, V. V., Boyko, V. P., Agranovsky, A. A., and Koonin, E. V. 1991. Phylogeny of capsid proteins of rod-shaped and filamentous RNA plant viruses: Two families with distinct patterns of sequence and probably structure conservation. Virology 184:79-86.

17. Dolja, V. V., Haldeman-Cahill, R., Montgomery, A. E., Vandenbosch, K. A., and Carrington, J. C. 1995. Capsid protein determinants involved in cell-to-cell and long distance movement of tobacco etch potyvirus. Virology 206:1007-1016.

18. Eagles, R. M., Gardner, R. C., and Forster, R. L. S. 1990. Nucleotide sequence of the tamarillo mosaic virus coat protein gene. Nucleic Acids Res. 18:7166.

19. Felsenstein, J. 1993. PHYLIP (Phylogeny Inference Package) Version 35C. Department of Genetics, University of Washington, Seattle.

20. Fenlon, J. S., and Sopp, P. I. 1991. Some statistical considerations in the determination of thresholds in ELISA. Ann. Appl. Biol. 119:177-189.

21. Fribourg, C. E., and Nakashima, J. 1984. Characterization of a new potyvirus from potato. Phytopathology 74:1363-1369.

22. Fribourg, C. E., and de Zoeten, G. A. 1970. Antiserum preparation and partial purification of potato virus A. Phytopathology 60:1415-1421.

23. Gal-On, A., Antignus, Y., Rosner, A., and Raccah, B. 1992. A zucchini yellow mosaic virus coat protein gene mutation restores aphid transmissibility but has no effect on multiplication. J. Gen. Virol. 73:2183-2187.

24. Goodman, R. N., and Novacky, A. J. 1994. The Hypersensitive Reaction in Plants to Pathogens. A Resistance Phenomenon. The American Phytopathological Society, St. Paul, MN.

25. Harrison, B. D., and Robinson, D. J. 1988. Molecular variation in vectorborne plant viruses: Epidemiological significance. Phil. Trans. R. Soc. Lond. (Ser. B) 321:447-462.

26. Hooker, W. J. 1981. Compendium of Potato Diseases. The American Phytopathological Society, St. Paul, MN.

27. Huet, H., Gal-On, A., Meir, E., Lecoq, H., and Raccah, B. 1994. Mutations in the helper component protease gene of zucchini yellow mosaic virus affect its ability to mediate aphid transmissibility. J. Gen. Virol. 75: 1407-1414.

28. Jagadish, M. N., Shukla, D. D., Gough, K. H., Tulloch, P. A., Whittaker, L. A., and Shukla, D. D. 1991. Expression of potyvirus coat protein in Escherichia coli and yeast and its assembly into virus-like particles. J. Gen. Virol. 72:1543-1550.

29. Jones, R. A. C. 1990. Strain group specific and virus specific hypersensitive reactions to infection with potyviruses in potato cultivars. Ann. Appl. Biol. 117:93-105.

30. Legavre, T., Maia, I. G., Casse-Delbart, F., Bernardi, F., and Robaglia, C. 1996. Switches in the mode of transmission select for or against a poorly aphid-transmissible strain of potato virus $\mathrm{Y}$ with reduced helper component and virus accumulation. J. Gen. Virol. 77:1343-1347.

31. MacLachlan, D. S., Larson, R. H., and Walker, J. C. 1953. Strain Rela- tionships in Potato Virus A. Res. Bull. 180. University of Wisconsin, Madison.

32. Maia, I. G., Haenni, A.-L., and Bernardi, F. 1996. Potyviral HC-pro: A multifunctional protein. J. Gen. Virol. 77:1335-1341.

33. Matthews, R. E. F. 1949. Studies on potato virus X. I. Types of change in potato virus X infections. Ann. Appl. Biol. 36:448-459.

34. Puurand, Ü., Mäkinen, K., Baumann, M., and Saarma, M. 1992. Nucleotide sequence of the 3'-terminal region of potato virus A RNA. Virus Res. 23:99-105.

35. Puurand, Ü., Mäkinen, K., Paulin, L., and Saarma, M. 1994. The nucleotide sequence of potato virus A genomic RNA and its sequence similarities with other potyviruses. J. Gen. Virol. 75:457-461.

36. Puurand, Ü., Valkonen, J. P. T., Mäkinen, K., Rabenstein, F., and Saarma, M. 1996. Infectious in vitro transcripts from the cloned cDNA of the potato A potyvirus. Virus Res. 40:135-140.

37. Richter, J., Rabenstein, F., Proll, E., and Vetten, H. J. 1995. Use of crossreactive antibodies to detect members of Potyviridae. J. Phytopathol. 143:459-464.

38. Rodriguez-Cerezo, E., Klein, P. G., and Shaw, J. G. 1991. A determinant of disease symptom severity is located in the 3'-terminal noncoding region of the RNA of a plant virus. Proc. Natl. Acad. Sci. U.S.A. 88:9863-9867.

39. Sambrook, J., Fritsch, E. F., and Maniatis, T. 1989. Molecular Cloning. A Laboratory Manual. Cold Spring Harbor Laboratory, Cold Spring Harbor, NY.

40. Shukla, D. D., Strike, P. M., Tracy, S. L., Gough, K. H., and Ward, C. W. 1988. The $\mathrm{N}$ and $\mathrm{C}$ termini of the coat proteins of potyviruses are surface-located and the $\mathrm{N}$ terminus contains the major virus-specific epitopes. J. Gen. Virol. 69:1497-1508

41. Shukla, D. D., Ward, C. W., and Brunt, A. A. 1994. The Potyviridae. CAB International, Littlehampton, United Kingdom.

42. Smith, D. B., McAllister, J., Casino, C., and Simmonds, P. 1997. Virus 'quasispecies': Making a mountain out of a molehill? J. Gen. Virol. 78: 1511-1519.

43. Thornbury, D. W., Patterson, C. A., Dessens, J. T., and Pirone, T. P. 1990. Comparative sequence of the helper component (HC) region of potato virus $\mathrm{Y}$ and a $\mathrm{HC}$-deficient strain, potato virus $\mathrm{C}$. Virology 178: 573-578.

44. Towbin, H., Staehelin, T., and Gordon, J. 1979. Electrophoretic transfer of proteins from polyacrylamide gels to nitrocellulose sheets: Procedure and some applications. Proc. Natl. Acad. Sci. U.S.A. 76:4350-4354.

45. Valkonen, J. P. T., Jones, R. A. C., Slack, S. A., and Watanabe, K. N. 1996. Resistance specificities to viruses in potato: Standardization of nomenclature. Plant Breed. 116:433-438

46. Valkonen, J. P. T., and Palohuhta, J. P. 1996. Resistance to potato virus A and potato virus $\mathrm{Y}$ in potato cultivars grown in Finland. Agric. Food Sci. Finl. 5:57-62.

47. Valkonen, J. P. T., Puurand, Ü., Slack, S. A., Mäkinen, K., and Saarma M. 1995. Three strain groups of potato A potyvirus based on hypersensitive responses in potato, serological properties, and coat protein sequences. Plant Dis. 79:748-753.

48. van der Vlugt, R. A. A., Leunissen, J., and Goldbach, R. 1993. Taxonomic relationships between distinct potato virus $\mathrm{Y}$ isolates based on detailed comparison of the viral coat proteins and $3^{\prime}$-nontranslated regions. Arch. Virol. 131:361-375.

49. Whetzel, H. H. 1929. The terminology of phytopathology. Proc. Int. Congr. Plant Sci. 2:1204-1215.

50. Xiao, X. W., Frenkel, M. J., Teakle, D. S., Ward, C. W., and Shukla, D. D. 1993. Sequence diversity in the surface-exposed amino-terminal region of the coat proteins of seven strains of sugarcane mosaic virus correlates with their host range and other biological properties. Arch. Virol. 132:399-408.

51. Yang, Z. N., and Mirkov, T. E. 1997. Sequence and relationships of sugarcane mosaic and sorghum mosaic virus strains and development of RTPCR-based RFLPs for strain discrimination. Phytopathology 87:932-939. 